\title{
The impact of religious affiliation on trust \\ in the context of electronic commerce
}

\author{
Haytham Siala $^{\mathrm{a}, *, 1}$, Robert M. O'Keefe ${ }^{\mathrm{b}}$ and Kate S. Hone ${ }^{\mathrm{a}}$ \\ ${ }^{a}$ Department of Information Systems and Computing, \\ Brunel University, \\ Uxbridge, Middlesex, UB8 3PH \\ ${ }^{\mathrm{b}}$ School of Management, University of Surrey \\ Guildford, Surrey, GU2 7XH, UK
}

* Corresponding author: Tel +442088171039 Fax +44 2088171247
${ }^{1}$ Present address: Preston University Middlesex, 23 Clayton Road, Hayes, UB3 1AN,
United Kingdom

Email addresses: haytham.siala@preston.ac (Haytham Siala),r.okeefe@surrey.ac.uk (Robert O’Keefe), kate.hone@brunel.ac.uk (Kate Hone). 


\begin{abstract}
There is currently a growing literature on the role that trust plays in encouraging consumers to engage in e-commerce transactions. Various models have been proposed which aim to identify both the antecedents and outcomes of trust displayed towards e-commerce web sites. Increased trust is generally shown to increase positive user attitude which in turn is linked to increased willingness to buy. Studies have shown the antecedents of trust include variables such as the perceived reputation and size of the vendor organisation. The current paper explores the role of cultural variables as antecedents of trust with the main emphasis being on religious affiliation. Participants recruited from Christian, Muslim and other faiths were asked to interact with online bookstores identified as Christian, Muslim or Neutral. Trust and attitudes towards the web sites were measured and this data was used to test the hypothesis that same-religion sites would be trusted and liked more than other religion or neutral sites. This hypothesis was partially supported, but only for the Muslim participants. It was found that the Muslim group expressed significantly more trust in the Muslim site compared to the Christian site. They also expressed significantly more positive attitudes towards the Muslim online bookstore than the other two sites. The implications of these result for theories of web based trust and attitude are discussed along with the practical implications of the findings.
\end{abstract}

Keywords: Trust; Electronic Commerce; Culture; Religion. 


\section{Introduction}

With the growth of internet shopping it has become increasingly important to understand the factors which influence consumer purchase decisions in the web context. Trust is one variable which is receiving considerable attention since it seems likely that consumers will prefer to buy from sites which they trust; indeed lack of trust is often cited as a significant barrier to e-commerce adoption (Hoffman et al., 1999; Egger, 2002). Studies such as Jarvenpaa et al (2000) have supported the idea that there is a relationship between trust in an online store and willingness to buy. Studies have also suggested a number of factors which contribute to increased trust in a web site including the characteristics of the organisation running the site (e.g. Jarvenpaa et al., 2000) and the interface characteristics of the sites themselves (e.g. Kim and Moon, 1998, Egger 2002).

The global nature of electronic retailing has recently led researchers to question whether the trust effects that they have identified generalise across different cultures. They have also begun to question whether there might be any significant differences between cultures in their trust of e-commerce stores. This paper considers the nature of the relationship between culture and trust in the e-commerce context. It asks whether a consumer's cultural affiliation can itself act as an antecedent to trust. The study uses religious identification to define cultural in-groups. It tests the hypothesis that participants will trust and like an e-commerce site affiliated to their own religion more than one affiliated to a different religion or to no religion. As well as providing practical guidance for electronic retailers, the results will contribute to the ongoing development of our understanding of the nature of trust in the e-commerce context.

The paper proceeds as follows. In the next sections, we briefly review some of the current literature on trust in the e-commerce context. We then review the relationship between trust, culture and religion and present the main research questions to be addressed in the paper. An empirical study of 91 participants, identified by their religious affiliation, is then presented and the results discussed. The paper ends with a discussion of the impact of religious affiliation on trust in the context of e-commerce. 


\section{Trust in the e-commerce context}

Definitions of trust vary from one context to another. Husted (1989) argues that trust is complicated due to the wide spectrum of approaches that define and describe it. In general the concept of trust involves a relationship between two entities, the trustor (the entity who trusts) and the trustee (the entity being trusted) (Grandison and Sloman, 2000). It is also generally recognised that trust is only a relevant concept when there is an element of risk or uncertainty inherent in the relationship between the trustor and trustee; a trustor must take risks that leave them vulnerable to the actions of the trustee (Hosmer, 1995). Internet purchasing certainly meets this criterion. Research strands can be differentiated on the basis of the types of parties involved in the trust relationship. These span one-to-one human to human relationships (typically studied within the domain of human psychology), humancomputer relationships (characterised by the classic work on trust in automation in $\mathrm{HCI}$ ) and one-to-many relationships such as between an individual and an organisation. It is with this latter type of trust relationship that we are concerned here, specifically it is the trust which an individual consumer holds in a web-based retail organisation.

In recent years a number of researchers have begun to investigate the role of consumer trust in e-commerce purchase decision making and several models have been developed (e.g. Egger, 2002; Jarvenpaa et al., 2000; Lee and Turban, 2001; Tan and Thoen, 2000). In such models trust is generally seen as a factor which can affect a consumer's willingness to buy. For instance in Tan and Thoen's (2000) model of trust for electronic commerce, a trustor's level of trust is assumed to need to reach a threshold level before they will be willing to engage in a transaction. The Internet Consumer Trust Model (Jarvenpaa et al., 2000) hypothesises a positive relationship between trust in an online store and willingness to buy. It also proposes that this relationship is mediated by attitude (a positive relationship) and risk perception (a negative relationship). Support for this model has been obtained through empirical studies in a number of countries including Australia, Finland and Israel (Jarvenpaa and Tratinsky, 1999). 
Researchers are also concerned with identifying the antecedents of trust in ecommerce stores. Kim and Moon (1998) provide empirical results which suggest that the visual features of a customer interface, specifically use of graphics and colour, can be manipulated in order to induce feelings of trustworthiness. Egger's (2002) Model of Trust for Electronic Commerce (MoTEC) proposes a number of factors which are important for the development and maintenance of trust. These are grouped into categories of pre-purchase knowledge (including store reputation), interface properties and informational content (for instance information provided by the store about their policies/guarantees).

\section{Trust and culture}

There are several reasons to assume that culture may be an important factor in on-line trust. Some studies have found that ingrained cultural values influence trust (Hofstede, 1998, Staw and Cummings, 1980). In general, trust in its cultural context is credited with being the social 'glue' for sustaining bonds between members of cultural groups (Trianis, 1995; Turner, 1987). When a number of people share common values and personality traits usually induced by cultural forces, they form a group, which they identify with, known as reference groups or group affinities. This builds in-group trust. These groups have a strong influence on an individual's beliefs, evaluations and the buying decision process (Howard, 1994). Consumers use role models and opinion leaders as a reference point to form their own attitudes and behaviour (Phipps and Simmons, 1998-99). Individuals are more likely to perceive members outside their social circles as untrustworthy than they are to perceive their in-group members (Brewer, 1979). Turner (1987) observed that individuals tend to affiliate to others who possess identical demographic attributes.

Jarvenpaa and Tratinsky (1999) suggest that the cultural background of a web consumer may act as an antecedent of trust. They explicitly considered the individualismcollectivism dimension of culture since this is thought to show the strongest variation across cultures (Hofstede, 1980). In a collectivist culture, an individual is regarded as a part of the 
group that s/he affiliates to and a high degree of interdependence among individuals prevails in the group (Hofstede, 1998). Collectivists' behaviour is usually regulated by group norms. Credit or blame is a 'group' responsibility and strong distinctions are made between in-group and out-group members. This is in contrast to individualist cultures where the distinction between in-group and out-group members often overlaps or is altogether non-existent (Zeynep and Durairaj, 2000). Further, collectivists value homogeneity within in-groups (Triandis, 1995). Thus, they are more willing to trust individuals and sub-groups within the same culture; this is a strong example of in-group trust.

Jarvenpaa and Tratinsky (1999) suggest that individualists, on the other hand, are characterised as having a utilitarian view of exchange which leads them to trust more widely (since this would be expected lead to better outcomes in general). Jarvenpaa and Tratinsky (1999) therefore hypothesised that consumers from individualistic cultures would exhibit higher trust (than those from collectivist cultures) in specific internet stores. However, the results of their study, comparing participants from Australia (an individualistic society) and Israel (a collectivist society), did not provide support for this hypothesis. They cite several limitations in their study which may have affected the results. One is that they measured culture by varying country alone, ignoring the fact that within-country cultural differences can sometimes be large. It may therefore be more appropriate to choose culturally defined ingroups from within a single country when conducting this kind of research. Another point which can be made about Jarvenpaa and Tractinsky's (1999) research is that although they noted that collectivists are likely to base their trust on relationships with in-group members, they did not explore this at all within their study.

The research reported here also takes the individualistic-collectivist cultural variable as its starting point. We have chosen to explore the role of membership in a collectivist culture in the formation of trust in online stores. As discussed above it is known that members of a collectivist culture assign a higher level of trust to others from the same ingroup than to those from outside. The question we address is whether this effect also applies to interactions with an interface, particularly a Web-based electronic commerce interface. 
There is growing evidence suggesting that humans respond socially and naturally to media (including computer interfaces) and that these responses are unconscious (Reeves and Nass, 1996). This certainly supports the contention that trust effects observed within cultural ingroups may transfer to the web context, given appropriate cues. Specifically we hypothesise that web-sites providing cues suggesting that they are from the same cultural group as participants from a collectivist culture will be trusted more than equivalent web-sites.

In order to explore the proposed relationship between trust and culture, we needed to identify participants from collectivist cultures. Given the problem that culture may vary significantly, even within a single country, we decided to use religious identification to classify our cultural in-groups. According to Iannaccone (1995), Islam, Judaism and Christianity share the traits of a collectivist culture. Devout followers of such religions are expected to abide by the rules set by their religious doctrines, for example, attending regularly weekly worship services and being strictly committed to the religious practices and membership of the group (Iannaccone, 1995; Solomon, 1999; Stark and Glock, 1968).

Trust in religious groups is usually nurtured by cultural values, which are acquired through the teachings of parents, the older generation and ministers of religions. Membership of a collectivist religion thus provides a good example of where in-group trust should be present. Moreover, we can conveniently identify members of a religion, and investigate their predisposition to trust under a set of cues and interfaces that either match (or do not) their own religion. Religion is a visible example of an antecedent to trust. We have chosen to use identification with the collectivist religions of Christianity and Islam in our research. Using two collectivist religions enables us to test the generalizability of any effects found. Islam is also interesting as it provides explicit guidance on commerce behaviour; Metwally (1997) contends that in Islam it is expected that the principle of co-operation between a buyer and a seller should be practised at both the corporate and individual level of commerce.

\subsection{Research hypotheses}

On the basis of the discussion above we propose the following research hypotheses: 
H1: Members of a collectivist religion will trust a same-religion web-site more than a neutral web-site or other religion web-site.

This hypothesis can be restated more specifically, for the religious groups used in this study, thus:

HIa: Members of the Muslim religion will trust a Muslim web-site more than a neutral web-site or other religion web-site.

H1b: Members of the Christian religion will trust a Christian web-site more than a neutral web-site or other religion web-site.

H2: Members of a collectivist religion will express more positive attitudes towards a samereligion web-site than a neutral web-site or other religion web-site.

Again this hypothesis can be restated more specifically as:

H2a: Members of the Muslim religion will express more positive attitudes towards a Muslim web-site than a neutral web-site or other religion web-site.

H1b: Members of the Christian religion will express more positive attitudes towards a Christian web-site than a neutral web-site or other religion web-site.

Note that $\mathrm{H} 2$ follows from $\mathrm{H} 1$, since theories of trust suggest that trust is related to attitude.

The following sections describe the research which was followed in order to investigate these hypotheses. Note that the scope of this research is confined to initial trust attitude formation.

\section{Empirical work}

An empirical study with 91 participants was conducted to explore the relationship between religious identification and trust in on-line stores. The experimental task involved participants interacting with religious or neutral e-commerce book stores. Questionnaire responses were used to measure the main dependent variables of web-based trust and webbased attitude. A separate questionnaire was used to measure demographic characteristics of 
the sample together with the extent of their religious affiliation and web experience. The next section details the development of the measurement constructs used in this research. The following sections describe the method adopted for the empirical study and the results obtained.

\subsection{Construct measurement}

A number of measures were developed and used in this research. Where measures were developed from scratch, we followed the procedure recommended by DeVellis (1991) and Bearden and Netemeyer (1999) for the development of psychological and latent construct measures. This involved the initial development of a 'pool' of items intended to capture the construct. The Likert and categorical scaling procedures were used for developing the constituent items of the constructs following the guidelines provided by Zikmund (1977). To counter for the response set of acquiescence (the tendency for people to agree with attitude statements), we reversed the Likert scale rating and the direction of the wording of some items (DeVellis, 1991). The resulting items were tested in a pilot trial (involving 50 participants) and some items were reworded to remove ambiguities identified during this trial.

It is argued that the convergent loadings of items on a separate factor is a trait of construct validity (Bearden and Netemeye, 1999; DeVellis 1991) and that in general, factors extracted from a factor analysis are assumed to represent the validity of the underlying latent constructs being investigated in a research study (DeVellis, 1991). We have therefore performed a factor analysis on the constituent items representing the different constructs to see if they are valid. The Principal Components method of extraction was adopted with a direct oblimin rotation. This rotation is useful when it is expected that the hypothetical factors will be correlated with one another (Kline, 1994). During the analysis only factors represented by three or more items were retained following the advice of Tabachnick and Fidell (1996). Cronbach's Alpha is used as a measure of the internal consistency of each scale used. The questionnaire items making up each of the scales used are shown in the Appendix. Reverse scored items are identified where applicable. 


\subsubsection{Dependent variables}

Measures of web-based trust and web-based attitude were developed following the procedure described above. The initial set of items was generated from a review of the literature discussing these latent constructs. The sources consulted in the development of the webbased trust items include Pearce (1974), Rotter (1967), Michalos (1990), Wang et al. (1998), Butler (1991), Deutsch (1958), Jones and George (1998) and Giffin (1967). The sources consulted in the development of the web-based attitude measure include Howard (1994), Proctor (1997) and O'Keefe et al. (2000). Following the pilot study a final version of the questionnaire was produced with seven items intended to measure web-based trust and ten items intended to measure web-based attitude. The questionnaire also included an 'intention to buy' item.

Following factor analysis three items measuring web-based trust were retained $($ Cronbach's Alpha $=0.88)$ and ten items measuring web-based attitude were retained $($ Cronbach's Alpha $=0.93)$. Intention-to-buy loaded on the web-based attitude factor and was therefore included within this general attitude measure. Cronbach's Alpha values of 0.80 or more are generally required for widely used scales (Igbaria and Parasuraman 1991) and both of our measures meet this criterion. There was a significant correlation $(p<0.05)$ between the scores on the measures of web-based trust and web-based attitude. This is in line with models which posit on-line trust acts an antecedent to attitude and willingness to buy (e.g. Jarvenpaa et al 2000).

\subsubsection{Demographic variables}

Several categorical demographic measures were used including one for the independent variable of religious identification (Christian, Muslim, none-or-other), as well as gender and ethnicity. In addition a number of demographic scales were used or developed to measure variables that might be expected to be important in the interpretation of the results, namely 
degree of religious affiliation or commitment, and experience in using computers and the world wide web.

While our main concern was establishing which religious group our participants identified with, we were also keen to check the extent of their religious commitment. This was measured using a scale developed by Stark and Glock (1968). We also wanted to establish the extent to which religious identification affected the participants' general buying habits, in particular the extent to which they were inclined to buy from within their own religious group. To measure this construct we adapted the consumer ethnocentrism scale or 'CETSCALE' developed by Shimp and Sharma (1987) so that it referred to religion rather than ethnicity. We refer to our new measure as the consumer religio-centrism scale. The validity of the scales was checked through factor analysis and as a result some of the original items were omitted. Nine items measuring religious commitment were retained (Cronbach's Alpha $=0.92)$ and seven items measuring consumer religio-centrism were retained $($ Cronbach's alpha $=0.86)$. There was a significant correlation $(\mathrm{p}<0.05)$ between these two measures.

Web experience (in years) was also measured because studies of interaction with ecommerce have found differences in the responses of experienced and less experienced individuals (e.g., Jarvenpaa and Todd, 1997; O'Keefe et al., 2000).

\subsection{Method}

\subsubsection{Experimental design}

A pseudo-experimental approach was used in the empirical study. A 3 x 3 mixed-factorial design was used. The naturally occurring variable of religious identification of the participants was used as the between subjects independent variable with three levels: Christian, Muslim and None-or-Other. The religious affiliation displayed by an e-commerce web site was used as the within-subjects independent variable, again with three levels: 
Christian, Muslim and Neutral. The dependent variables were web-based trust and web-based attitude.

One advantage of choosing an experimental approach over, for instance, structural equation modelling is that the sample sizes required are considerably smaller (e.g. Tabachnick and Fidell, 1996, suggest that for small to medium size structural equation models a sample size of 200 is adequate, though larger samples are preferred). More importantly our hypotheses in this research are such that they naturally fit an experimental approach, since they posit differences between ratings of different religion sites depending on the religious identification of the participants. However, it is worth noting that since this work is pseudoexperimental, relying on naturally occurring participant groups, questions of causality cannot be resolved unambiguously.

In order to operationalise the independent variable of the displayed religion of the web site we chose to use naturally occurring web sites as our stimulus materials. We chose to use online bookstores since this category of purchase has been the focus of a number of other studies (e.g., Jarvenpaa and Tractinsky, 1999). We were also able to find web sites within this category which were clearly affiliated to particular religions. The use of real web sites increases the ecological validity of the results, but also introduces several problems. The content and layout of the sites could have changed over the course of the studies, which were run over several days. We could not easily download the site and work with a local copy (as done, for example, by O'Keefe et al., 2000) since sites are database and search driven, dynamically generating pages based upon requests and user actions. In addition we were not able to control for the Web site layout, perceived usability, ease-of-use and other extraneous variables that could have varied across sites. We did, however, choose sites that did not use third party seals or similar exogenous measures of trust that might bias results.

Our hypotheses were directly tested through the inclusion of the Christian and Muslim groups of participants. However, since we were not able to control for all of the features of the web sites used, we also included a control group of participants, not affiliated 
to either of the target religions. This allowed us a means to check for the role of extraneous (non-cultural) variables. If the pattern of responses for all three groups across the three web sites were similar it would suggest that the results could be explained by non-cultural factors alone. If they vary by religious identification for the religious groups, and this pattern differs from that observed for the non-affiliated participants, we have stronger grounds for attributing the findings to the effects of culture.

\subsubsection{Participants}

Participants in this study were recruited from within the student population at Brunel University, West London. This population was chosen since it is culturally diverse and generally experienced in using the web. Participants were invited using various methods including e-mailing online religious groups at Brunel University, and placing fliers around the University. An incentive of $£ 20 \mathrm{UK}$ was offered in order to encourage participants to take part. The benefits in terms of the increased participation rates achieved through offering this incentive were thought to outweigh any possible risk that the use of incentives may affect questionnaire responses (e.g. see Singer et al., 1999).

Ninety one participants took part in the study. Twenty nine were categorised as Christian, thirty eight as Muslim and twenty four as None-or-Other religion. Their demographic characteristics and web experience are summarised in Table 1.

\section{-------[insert Table 1 about here]-------}

The data indicate that the majority of participants within all religious categories are experienced web users. However, there are large gender differences between the religious groups; nearly $80 \%$ of the Muslim sample are male compared to $62 \%$ in the Christian sample and $50 \%$ in the no-or-other religion group.

Mean scores on the religious commitment scale and consumer religio-centrism scale are shown in Table 2 and illustrated in Figures 1 and 2.

------[insert Table 2, Figure 1 and 2 about here]------ 
The Muslim participants in our sample appear to be more strongly committed to their religion than the participants in the other groups, they also appear to be more consumer religio-centric than participants in the other groups. These differences were tested using the Krustal-Wallis test (this non-parametric alternative to one-way ANOVA was used since the assumption of homogeneity of variance was not met for these data sets). It was found that religious commitment varied with religious identification in our sample $($ Chi-Square $(2)=52.2$, $\mathrm{p}<0.001$ ). Post hoc Mann Whitney tests confirmed that there are significant differences between the Muslim participants and Christian participants $(\mathrm{U}=111, \mathrm{p}<0.001)$, and between the Muslim and the None-or-Other religion participants $(\mathrm{U}=24.5, \mathrm{p}<0.001)$. There was also a significant difference between the Christian and the None-or-Other participants $(\mathrm{U}=222.5$, $\mathrm{p}<0.05)$. It was also found that consumer religio-centrism varies with religious identification in our sample (Chi-Square(2)=51.7, $\mathrm{p}<0.001)$. The significant differences are between the Muslim participants and Christian participants (U=69.5, $\mathrm{p}<0.001)$, and between the Muslim and the None-or-Other religion participants $(\mathrm{U}=49.5, \mathrm{p}<0.001)$. These differences need to be borne in mind when analysing and interpreting the data from this study.

\subsubsection{Procedure and experimental tasks}

All experimental tasks during this study were performed in a laboratory at Brunel University in order to control for any effects due to physical location. Each participant interacted with three Web sites; a same-religion site, a different-religion site and a neutral site. The neutral site in both cases was www.bol.com. The same-religion site for the Muslim participants was www.dar-us-salam.com (for Christian participants this was the other-religion site); for Christian participants the same-religion site was www.christianbooks.com (which was the other-religion site for the Muslim participants). At the start of the experimental session participants received a printed instruction sheet, informing them of their right to withdraw at any time and detailing the tasks to be completed. They were asked to explore each web site for approximately 20 minutes before filling out a questionnaire based on their experience of 
it. Following completion of this part of the study, participants were asked to complete the demographic questionnaire.

\subsection{Results}

\subsubsection{Results for web-based trust}

The mean ratings of Web-based trust for each site by each group of participants are summarised in Table 3. These data are also represented in Figure 3.

------[insert Table 3 and 4 and Figure 3 about here]------

A 3 x 3 mixed-factorial analysis of covariance was performed on ratings of web-based trust (see Table 4). The within-subjects independent variable consisted of displayed religion of the web-site (Christian, Muslim and None). The between-subjects independent variable was religious identification of the participant (none-or-other, Christian and Muslim). Gender was used as a covariate to remove effects due to the uneven distribution of gender throughout the groups of participants. Analyses were performed by SPSS using type III adjustment for unequal sample size.

After adjustments by the covariate, a significant multivariate main effect was observed with $\mathrm{F}(2,86)=3.67, \mathrm{p}<0.05$. There was also a significant interaction effect with religious identification of the participant $(\mathrm{F}(4,86)=5.15, \mathrm{p}<0.05)$.

A test of the within-subjects effects showed a significant main effect of site religion $(\mathrm{F}(1,87)=6.75, \mathrm{p}<0.05)$ and a significant interaction effect between site religion and religious identification $(\mathrm{F}(2,87)=6.0, \mathrm{p}<0.05)$. There were no significant between-subjects effects.

Planned comparisons were conducted with the Muslim portion of the sample to test Hypothesis H1a, that members of the Muslim religion will trust a Muslim web-site more than a neutral web-site or Christian web-site. Note that since these were planned comparisons, using within-group data, the original (non-adjusted) means for web-based trust were used. It was found that the Muslim participants did express significantly more trust in the Muslim 
book site compared to the Christian book site $(\mathrm{t}(37)=-2.74, \mathrm{p}<0.05)$, however there was no significant difference between the mean trust rating for the Muslim site and the Neutral site.

Planned comparisons were conducted with the Christian portion of the sample to test Hypothesis H1b, that members of the Christian religion will trust a Christian web-site more than a neutral web-site or Muslim web-site. No significant differences were found so we cannot reject the null hypothesis.

Post-hoc comparisons were conducted to investigate the within-subjects effects for the none-or-other religion group. It was found that this group rated their trust in the Muslim book site as significantly lower than in either the Christian $(\mathrm{t}(23)=3.08, \mathrm{p}<0.05)$ or the Neutral book sites $(\mathrm{t}(23)=2.80, \mathrm{p}<0.05)$.

These results support the idea that trust in e-commerce web sites differs according to the religious affiliation displayed on the web site and that this difference is related to religious affiliation of the participants. Hypothesis H1, that participants will report increased trust in a same-religion web site compared to another religion or neutral site is partially supported, but only for the Muslim participants (Hypothesis H1a).

\subsubsection{Results for web-based attitude}

The mean ratings of Web-based attitude for each site by each group of participants are summarised in Table 4. These data are also represented in Figure 4.

------[insert Table 5 and 6 and Figure 4 about here]------

A $3 \times 3$ mixed-factorial analysis of covariance was performed on ratings of attitude toward the web sites (see Table 6). The within-subjects independent variable consisted of displayed religion of the web-site (Christian, Muslim and None). The between-subjects independent variable was religious identification of the participant (none-or-other, Christian and Muslim). The covariate was gender. Analyses were performed by SPSS using type III adjustment for unequal sample size. 
After adjustments by the covariate, a significant multivariate main effect was observed with $F(2,86)=10.65, \mathrm{p}<0.001$. There was also a significant interaction effect with religious identification of the participant $(F(4,86)=5.65$, $\mathrm{p}<0.001)$.

A test of the within-subjects effects showed a significant main effect of site religion $(\mathrm{F}(1,87)=13.57, \mathrm{p}<0.001)$ and a significant interaction effect between site religion and religious identification $(F(2,87)=11.64, \mathrm{p}<0.001)$. There were no significant betweensubjects effects.

Within-subjects planned comparisons were conducted with the Muslim portion of the sample to test hypothesis $\mathrm{H} 2 \mathrm{a}$, that Muslims would express more positive attitude towards a Muslim site compared to another religion site or a neutral site. It was found that the Muslim participants did express significantly more positive attitudes towards the Muslim site compared to either the Christian site $(\mathrm{t}(37)=-7.752, \mathrm{p}<0.001)$ or the Neutral site $(\mathrm{t}(37)=-$ $2.13, \mathrm{p}<0.05)$

Within-subjects planned comparisons were conducted with the Christian portion of the sample to test hypothesis $\mathrm{H} 2 \mathrm{~b}$, that Christians would express more positive attitude towards a Christian book site compared to another religion site or a neutral site. A significant difference was found between attitude towards the Christian site (same religion) and the Neutral site, but this was in the opposite direction to that predicted, with the neutral site being preferred over the Christian site $(\mathrm{t}(28)=-4.37, \mathrm{p}<0.001)$. No significant difference was found between attitude towards the Christian and the Muslim sites.

Post-hoc comparisons were conducted to investigate the within-subjects effects for the none-or-other religion group. It was found that this group expressed significantly more positive attitudes towards the Neutral site compared to either the Christian site $(\mathrm{t}(23)=6.02$, $\mathrm{p}<0.001)$ or the Muslim book site $(\mathrm{t}(23)=4.02, \mathrm{p}<0.01)$.

These results support the idea that attitude towards e-commerce web sites differs according to the religious affiliation displayed on the web site and that this difference is related to religious affiliation of the participants. Hypothesis $\mathrm{H} 2$, that participants will report more positive attitudes towards a same-religion web site compared to another religion or 
neutral site is supported, but only for the Muslim participants (i.e. Hypothesis H2a is supported). Contrary to hypothesis $\mathrm{H} 2 \mathrm{~b}$, the Christian participants actually held less positive attitudes towards a same religion site compared to a Neutral site.

\section{Discussion and conclusions}

The global nature of the internet allows e-commerce stores to market around the world. Within this context it is important for web retailers to understand how aspects of their sites may help to engender trust and positive attitude within members of particular cultural groups. The current paper has explored the role which consumer cultural identification plays in the initial formation of trust and attitude towards web-based stores which display culture-specific characteristics. The section below reviews the main findings. We then go on to discuss the limitations of the current study and to suggest ways in which this research could be extended.

\subsection{Main findings}

The main contribution of this paper is to show that trust and attitude in a web-based retailer can vary with culture, at least as represented by affiliation to a religion. Within one collectivist culture, identification with the Muslim religion, we have shown that in-group trust effects can transfer to the web context. Thus Muslims in our study were found to be more trusting of a Muslim site compared to a Christian site (though not compared to the Neutral site). Muslim participants also had significantly more positive attitudes towards the Muslim site than the neutral site and the Christian site. Since the attitude construct used in this study is closely related to willingness to buy, this finding suggests that this group would be more likely to buy from the Muslim site than the other two sites tested.

While the hypothesised relationships between trust and religious identification were supported for the Muslim participants, this was not the case with the Christian participants. We had predicted that Christians, as members of a collectivist religion, would trust and like a same religion site more than a neutral or other religion site. However, where significant differences were observed for the Christian sample it was in the opposite direction to that 
predicted, with the neutral site being liked better than the Christian site. Overall the pattern of responses given by the Christians was similar to those given by the None-or-Other religion group. This result could be interpreted as suggesting that the Christians are not using religious distinctions in forming their initial trust and attitude towards a web site. In the absence of culture effects we would expect bigger, more well-known stores to be trusted and liked better by participants (Jarvenpaa and Tractinsky, 1999). The observed preference for Bol.com, which is fairly well known in the $\mathrm{UK}$, is understandable in this context.

The lack of predicted effects with the Christian sample calls into question the generalisability of the findings with the Muslim sample to other collectivist religions. However, there are a number of potential explanations for the differential results obtained with the Christian and Muslim samples. The scores of these two groups on the religious commitment scale did differ significantly, so it may be that the Christians in our sample were simply not committed enough to their religion for this to play a part in their interactions with an e-commerce web site. Interestingly the Muslim and Christian participants also differed significantly in terms of how much they said religion affected their general purchasing decisions (as measured by the consumer religio-centrism scale). This supports the idea that the effects we have observed in our experiment may demonstrate a transfer of in-group attitudes from the general to the web context. What is not clear from the work is whether the differences we observed in consumer religio-centrism between the Muslims and Christians in our sample are due to the differences in religious commitment observed (an explanation supported by the correlation between these two variables) or whether it is the specific Muslim tradition of buying within their own culture which is important. Further research is needed to clarify this point.

Another potential explanation for the results obtained with the Christian sample concerns the choice of the Christian web site. At the time when the studies were conducted we could only identify religious book selling sites which were based in the US. The style of Christianity displayed on the site used may have differed significantly from the style practised by our study participants in the UK and may therefore not have engendered feelings of in- 
group belonging. Indeed the sites may actually have been perceived as out-group, reducing feelings of trust and liking.

The fact that the studies were conducted in the UK may also be relevant to the results obtained. Feelings of in-group affiliation generally thought to be increased by the presence of a salient out-group. Since the majority religion of the UK is Christianity, this out-group cue would be present for the Muslim group but not for the Christian group. It would be interesting to repeat this work within a predominantly Muslim country to see if the current results are replicated. It may be that within a non-Christian culture, Christians would trust a same-religion site more than a neutral or other religion site.

\subsection{Limitations and future work}

There are a number of limitations in this work that need to be taken into account when assessing the implications.

One limitation concerns the sampling where we have assumed homogeneity of religious identification within the religious groups used. However, both Christianity and Islam have experienced profound schisms that resulted in the inception of several religious factions such as Roman Catholics, Eastern Orthodox, and various Protestant groups in Christianity, and the Sunni and Shia sects in Islam (Hofstede, 1998). The definition of Christian sub-groups as collectivist is perhaps problematic; for example, the United States is a highly Christian country while being widely regarded as an individualist society. It is possible that stronger in-group effects could have been obtained had we defined our sample groups less broadly. Future work could examine this possibility by concentrating on specific religious sects, though the practical applicability of such research might be limited.

Another sampling issue is that our Christian and Muslim samples differed from one another in terms of religious commitment. We already discussed how this might have affected our results, however it is also possible that the differences we observed might reflect genuine population differences. Thus it may be that Muslims in the UK are, on average, more committed to the practice of their religion than Christians. If this were the case it could mean 
that the design of culturally compatible web sites would be more important for Muslim users. Further work would be needed to address this question.

The Muslim sample in our study also differed from the other samples in terms of gender mix. In our overall analysis we controlled for this by using gender as a covariate. While this procedure is often followed it is still seen as somewhat controversial (Tabachnick and Fidell, 1996). This does not affect the validity of the main experimental findings, since the main hypotheses were tested a priori using within group t-tests on the raw data. However it does call into question the role which gender plays in mediating responses to web sites. The relatively small number of female participants in the Muslim group also means that care needs to be taken in generalising the results to the female Muslim population in general. Future work should certainly try to control for gender effects and it may also be interesting to explicitly investigate the role of gender in this context. However, it is worth noting that we found it difficult to recruit female Muslim participants for our study. It is thus possible that the gender bias we found in the sample reflects gender differences in technological familiarity within the Muslim culture more generally; further research is needed to establish whether this is the case.

Another set of limitations relate to our use of real internet sites as the stimuli for the experimental studies. We have already discussed how the perceived size and reputation of the neutral site was probably greater than in the religion-specific sites used. Ideally in future work these known antecedents to trust should be controlled, for instance by choosing a less well known site to represent the 'neutral' category. The use of real world religious online bookstores in the studies is also somewhat problematic since it confounds the religious content of the books sold with the religious affiliation of the site in general. Intrinsic interest in the products sold would thus be expected to vary with religious identification of the participant and this may partially explain the attitude results (at least for the Muslim group). On the other hand it would be hard to explain the trust effects we observed simply by considering intrinsic interest in the products. Ideally, however, the products for sale would be 
constant across stimulus sites and only the religious affiliation would vary. In practice, using real web sites, it proved impossible to separate these factors.

In order to assuage some of the problems associated with using real sites, we introduced a control group of None-or-Other religion participants. The responses of these participants were intended to allow some ability to check for any differences in ratings between sites not directly attributable to cultural match or mismatch. However, interpretation of the results from this group is not straightforward since no participant can be considered culturally 'neutral'. While the similarities between the pattern of responses for the None-orOther and the Christian participants discussed above are interesting, we have to be careful to stress the speculative nature of any conclusions drawn from this data.

The use of online bookstores in the empirical studies provides a more general limitation in the research. While book sites have been the focus of a number of other studies there is evidence that different results may be obtained with different categories of purchase. Jarvenpaa et al. (2000), for instance, found different effects of store size on ratings of trust for book sites and for travel sites. Lowengart and Tractinsky (2001) investigated internet purchase decisions by risk category of the goods, comparing book buying (a low risk in terms of investment) to computer buying (high risk). They suggest that aspects of uncertainty and risk are more salient to consumers when they are purchasing high risk products such as computers. It is thus possible that any trust effects of religious or cultural affiliation would become more pronounced for higher risk purchases. This could be investigated in future work.

Finally, it must be remembered that we have used religious affiliation as an example of a cultural attribute, namely collectivism. We did not control for nationality, and it is likely that the interaction between nationality and religion is complex (such as the example of Christianity in the United States, as mentioned above). Further work might control for religion and, say, use Hofstede's concept of individualism rather than assume collectivism from religious affiliation. 
Despite the limitations of our work, we suggest that our approach is potentially important. Focussing on a particular aspect of trust, and then designing research where we predict that the aspect of trust should have some effect, is in direct contrast to studies that measure trust and try to relate it to other variables. Moreover, religion is an under researched aspect of individual differences in HCI, and we posit an important one. We believe that the initial results we have obtained in this field are promising. They have also allowed us to generate a number of further questions to be addressed through future research. 


\section{References}

Bearden, W.O., Netemeyer, R.G., 1999. Handbook of Marketing Scales (Second edn.). Thousand Oaks: Sage Publications.

Brewer, M.B., 1979. In-group bias in the minimal intergroup situation: a cognitivemotivational analysis. Psychology Bulletin 86, 307-324.

Butler, J.K., 1991. Towards Understanding and Measuring Conditions of Trust: Evolution of a Conditions of Trust Inventory. Journal of Management 17, 643-663.

Deutsch, M., 1958. Trust and suspicion. Journal of Conflict Resolution 2, 265-279.

DeVellis, R.F., 1991. Scale Development: Theory and Applications. London: Sage Publications.

Egger, F.N., 2002. Trust me, I'm an online vendor: towards a model of trust for e-commerce system design. CHI 2002.

Giffin, K., 1967. The contribution of studies of source credibility to a theory of interpersonal trust in the communication process. Psychological Bulletin 68, 104-120.

Grandison, T, Sloman, M., 2000. A survey of trust in internet applications. IEEE Communications Surveys, Fourth Quarter, 2-16.

Hoffman, D.L., Novak, T.P., Peralta, M., 1999. Building consumer trust online. Communications of the ACM 42, 80-85.

Hofstede, G., 1998. Cultures and Organizations. London: Harper Collins Business.

Hosmer, L.T., 1995. Trust: the connection link between organizational theory and philosophical ethics. Academy of Management Review, Vol 20, 379-403.

Howard, J.A., 1994. Buyer Behavior in Marketing Strategy (Second edn.). London: PrenticeHall.

Husted, B.W., 1989. Trust in business relations: directions for empirical research. Business and Professional Ethics Journal 8, 23-40.

Iannaccone, L.R., 1995. Risk, rationality and religious portfolios. Economic Inquiry 13, 285295.

Igbaria, M., Parasuraman, S., 1991. Attitudes towards microcomputers: development and construct validation of a measure. International Journal of Man-Machine Studies, 35, 553-573.

Jarvenpaa, S.L., Todd, P. A., 1997. Consumer reactions to electronic shopping on the world wide web. International Journal of Electronic Commerce 1:2, 59-88.

Jarvenpaa, S. L., Tractinsky, N., 1999. Consumer trust in an internet store: a cross-cultural validation. Journal of Computer-Mediated Communication, 5:2.

Jarvenpaa, S.L., Tractinsky, N., Vitale, M., 2000. Consumer trust in an internet store. Information Technology and Management, 1:1-2, 45-71.

Jones, G.R., George, J.M., 1998. The experience and evolution of trust: implications for cooperation and teamwork. Academy of Management Review 23:3, 531-547.

Kim, J., Moon, J.Y., 1998. Designing towards emotional usability in customer interfaces -trustworthiness of cyberbanking system interfaces. Interacting with Computers 10, 1 29.

Kline, P., 1994. An Easy Guide to Factor Analysis. London: Routledge.

Lee, M., Turban, E., 2000. A trust model for consumer Internet shopping. International Journal of Electronic Commerce, 6:1, 75-92. 
Lowengart, O., Tractinsky, N., 2001. Differential effects of product category on shoppers' selection of web-based stores: a probabilistic modeling approach. Journal of Electronic Commerce Research, 2:4, 12-26.

Metwally, M. M., 1997. Economic consequences of applying Islamic principles in Muslim societies. International Journal of Social Economics 24, 941-958.

Michalos, A., 1990. The impact of trust on business, international security, and the quality of life. Journal of Business Ethics 9, 619 - 638.

O'Keefe, R.M., Cole, M., Chau, P.Y.K., Massey, A., Montoya-Weiss, M., Perry, M., 2000. From the user interface to the consumer interface: results from a global experiment. International Journal of Human-Computer Studies 53, 611-628.

Pearce, W.B., 1974. Trust in Interpersonal Relationships. Speech Monographs 41, 236-244.

Phipps, R., Simmons, C., 1998-99. Understanding Customers. Oxford: ButterworthHeinemann.

Proctor, T., 1997. Essentials of Marketing Research. London. Pitman Publishing, Pearson Professional Ltd.

Reeves, B., Nass, D., 1996. The Media Equation: How people treat computers, television and new media like real people and places. Stanford: CSLI Publications.

Rotter, J.B., 1967. A new scale for the measurement of trust. Journal of Personality 35, 651665.

Shimp, T.A., Sharma, S., 1987. Consumer ethnocentrism: construction and validation of the CETSCALE. Journal of Marketing Research 24, 280-289.

Singer, E, Gebler, N. Raghunathan, T., Van Hoewyk, J., Katherine McGonagle, 1999. The effect of incentives in interviewer-mediated surveys. Journal of Official Statistics $15: 217-230$.

Solomon, M.R., 1999. Consumer Behavior: Buying, Having, and Being (Fourth edn.). Upper Saddle River, New Jersey: Prentice Hall, Inc.

Stark, Rwanda Glock, C.Y., 1968. American Piety: The Nature of Religious Commitment. California: University of California Press.

Staw, B.M., Cummings, L.L., 1980. Research in Organizational Behavior: An Annual Series of Analytical Essays and Critical Reviews. Greenwich, CT: JAI Press.

Tabachnick, B.G., Fidell, L.S., 1996. Using Multivariate Statistics (Third edn.). NY: HarperCollins College Publishers.

Tan, Y-H., Thoen, W., 2000. Towards a generic model of trust for electronic commerce. International Journal of Electronic Commerce 5:2, 61-74.

Triandis, H.C., 1995. Individualism and Collectivism. Boulder, Colorado: Westview Press.

Turner, J.C., 1987. Rediscovering the Social Group: A Self-categorization Theory. Oxford: Blackwell.

Wang, H., Lee, M.K.O., Wang, C., 1998. Consumer privacy concerns about internet marketing. Communications of the ACM 41, 63-70.

Zikmund, W.G., 1997. Business Research Methods (Fifth edn.). Orlando: The Dryden Press, Harcourt Brace College Publishers.

Zeynep, G.-C., Durairaj, M., 2000. Cultural variations in country of origin effects. Journal of Marketing Research 37, 309-327. 
TABLE 1. Characteristics of the sample cross-tabulated against religion $(\mathrm{N}=91)$.

\begin{tabular}{|c|c|c|c|c|}
\hline & Christian (\%) & Muslim (\%) & Others $(\%)$ & $\begin{array}{l}\text { Total within } \\
\text { sample (\%) }\end{array}$ \\
\hline \multicolumn{5}{|l|}{ Gender } \\
\hline Male & 62 & 79 & 50 & 65.9 \\
\hline Female & 38 & 21 & 50 & 34 \\
\hline \multicolumn{5}{|l|}{ Ethnicity } \\
\hline Arab & 0 & 29 & 0 & 12.1 \\
\hline Asian (Other) & 3 & 8 & 17 & 8.8 \\
\hline Bangladeshi & 0 & 3 & 0 & 1.1 \\
\hline Black African & 3 & 3 & 0 & 2.2 \\
\hline Caucasian & 3 & 0 & 0 & 1.1 \\
\hline Chinese & 0 & 0 & 25 & 6.6 \\
\hline European/White & 83 & 8 & 21 & 35.2 \\
\hline Hispanic & 3 & 0 & 0 & 1.1 \\
\hline Indian & 0 & 3 & 34 & 9.9 \\
\hline Kurdish & 0 & 3 & 0 & 1.1 \\
\hline Mauritian & 3 & 0 & 0 & 1.1 \\
\hline Pakistani & 0 & 39 & 0 & 16.5 \\
\hline Persian & 0 & 5 & 0 & 2.2 \\
\hline Srilankan & 0 & 0 & 4 & 1.1 \\
\hline \multicolumn{5}{|l|}{ Religious level } \\
\hline Conservative & 24 & 86 & 0 & 44 \\
\hline Moderates & 34 & 10 & 38 & 25.3 \\
\hline Liberals & 41 & 3 & 63 & 30.8 \\
\hline \multicolumn{5}{|l|}{ Usage of Internet } \\
\hline < 6 months & 0 & 0 & 0 & 0 \\
\hline 1 year & 10 & 3 & 4 & 5.5 \\
\hline 2-3 years & 28 & 39 & 30 & 33 \\
\hline$>3$ years & 62 & 58 & 68 & 61.6 \\
\hline
\end{tabular}

TABLE 2: Mean scores on the religious commitment scale and consumer religio-centrism scale.

\begin{tabular}{|l|c|c|}
\hline Religious identification & $\begin{array}{c}\text { Religious Commitment } \\
\text { Mean (standard deviation) }\end{array}$ & $\begin{array}{c}\text { Consumer Religio-Centrism } \\
\text { Mean (standard deviation) }\end{array}$ \\
\hline Christian & $2.72(0.88)$ & $1.39(0.52)$ \\
\hline Muslim & $4.11(0.58)$ & $2.83(0.77)$ \\
\hline None-or-Other Religion & $2.15(0.80)$ & $1.40(0.42)$ \\
\hline
\end{tabular}


FIGURE 1: Religious commitment by religious identification.

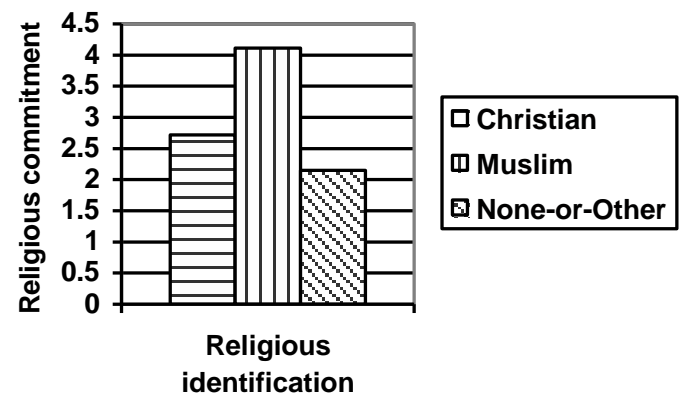

FIGURE 2: Consumer religio-centrism by religious identification.

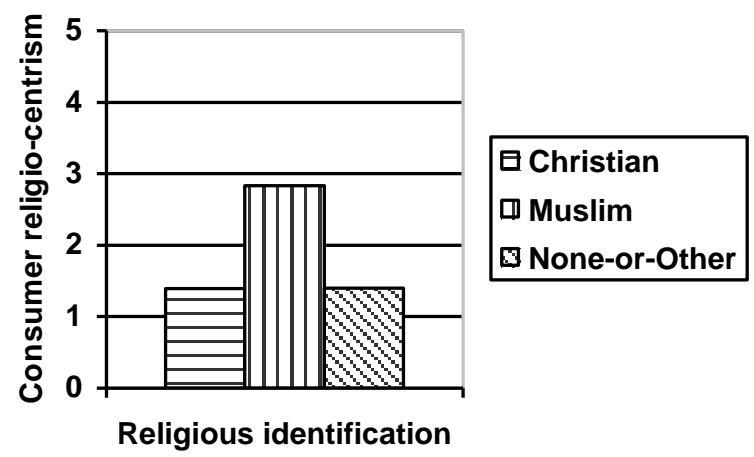

TABLE 3: Mean ratings of web-based trust.

\begin{tabular}{|l|c|c|c|}
\hline $\begin{array}{l}\text { Participant religious } \\
\text { identification }\end{array}$ & $\begin{array}{c}\text { Site Religion: } \\
\text { Christian }\end{array}$ & \multicolumn{2}{|l|}{ Muslim } \\
\hline Christian & 3.49 (s.d. 1.04) & 3.21 (s.d. 1.03) & 3.49 (s.d. 0.86) \\
\hline Muslim & 3.18 (s.d. 0.88) & 3.62 (s.d. 0.78) & 3.39 (s.d. 0.80) \\
\hline None-or-Other & 3.44 (s.d. 0.75) & 3.06 (s.d. 0.54) & 3.60 (s.d. 0.85) \\
\hline
\end{tabular}


FIGURE 3: Mean ratings of web-based trust.

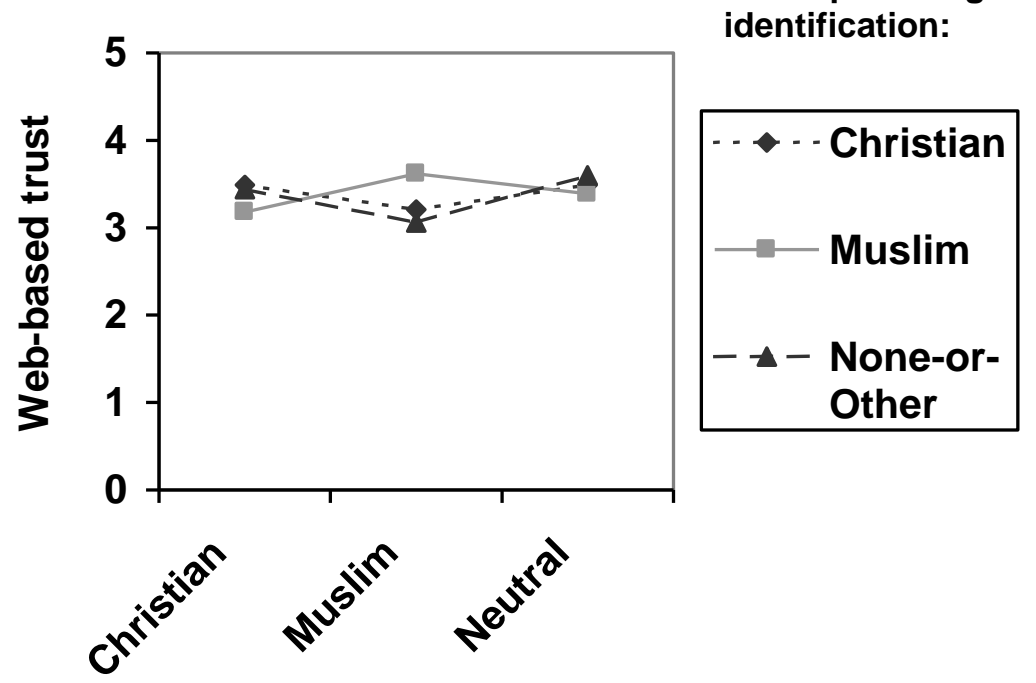

Web site religion

TABLE 4: Analysis of covariance of web-based trust.

\begin{tabular}{|l|l|l|l|l|l|}
\hline Source & $\begin{array}{l}\text { Sum of } \\
\text { Squares }\end{array}$ & df & $\begin{array}{l}\text { Mean } \\
\text { Square }\end{array}$ & F & Sig. \\
\hline Site religion & 3.677 & 1 & 3.677 & 4.529 & $\mathrm{p}<0.05$ \\
\hline Site religion x gender & 2.635 & 1 & 2.635 & 3.246 & n.s. \\
\hline Site religion x religious identification & 9.152 & 2 & 4.576 & 5.635 & $\mathrm{p}<0.05$ \\
\hline Error (site) & 70.643 & 87 & 0.812 & & \\
\hline
\end{tabular}

TABLE 5: Mean ratings of web-based attitude.

\begin{tabular}{|c|c|c|c|}
\hline $\begin{array}{l}\text { Participant religious } \\
\text { identification }\end{array}$ & $\begin{array}{r}\text { Site Religion: } \\
\text { Christian }\end{array}$ & Muslim & Neutral \\
\hline Christian & 2.50 (s.d. 0.94) & 2.22 (s.d. 0.69) & 3.39 (s.d. 0.65 ) \\
\hline Muslim & 2.39 (s.d. 0.77) & 3.85 (s.d. 0.94) & 3.18 (s.d. 0.92$)$ \\
\hline None-or-Other & 2.85 (s.d. 0.70$)$ & 2.53 (s.d. 0.51$)$ & 3.78 (s.d. 0.71) \\
\hline
\end{tabular}




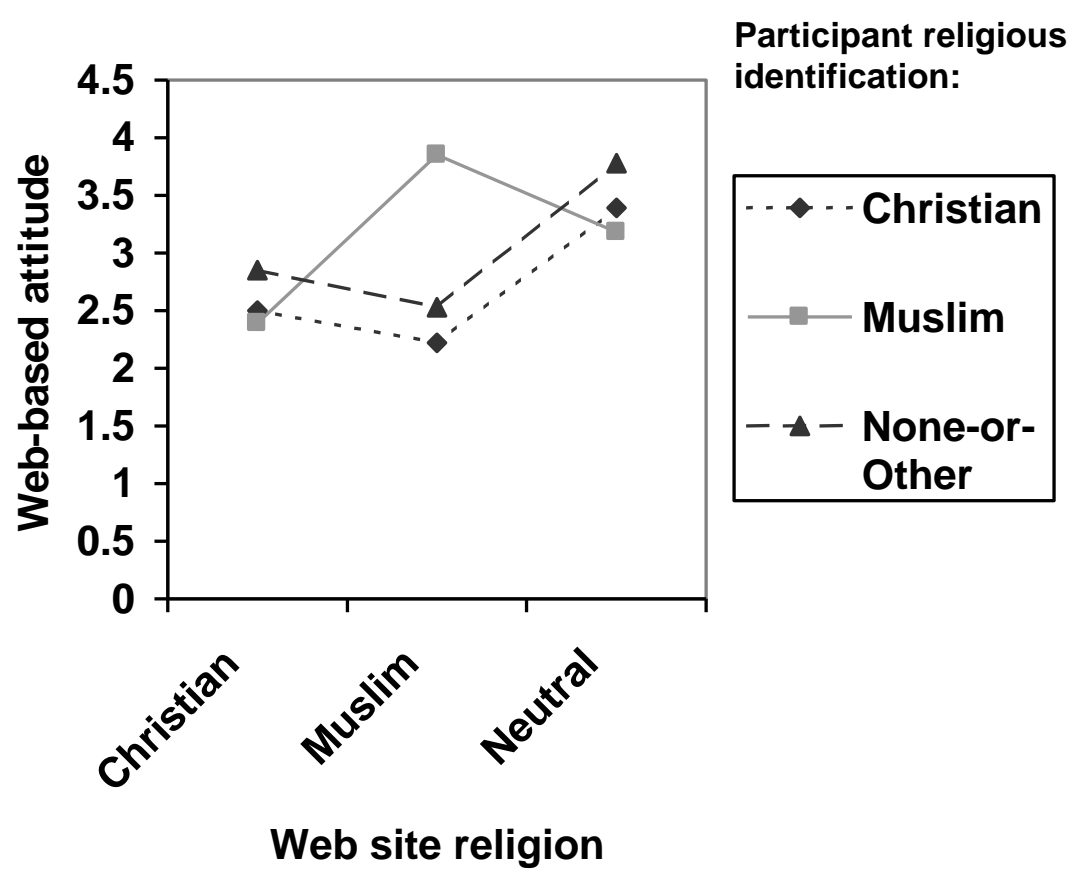

FIGURE 4: Mean ratings of web-based attitude.

TABLE 6: Analysis of covariance of web-based attitude.

\begin{tabular}{|l|l|l|l|l|l|}
\hline Source & $\begin{array}{l}\text { Sum of } \\
\text { Squares }\end{array}$ & df & $\begin{array}{l}\text { Mean } \\
\text { Square }\end{array}$ & F & Sig. \\
\hline Site religion & 8.572 & 1 & 8.572 & 16.906 & $\mathrm{p}<0.001$ \\
\hline Site religion x gender & 3.112 & 1 & 3.112 & 6.138 & n.s. \\
\hline Site religion x religious identification & 42.309 & 2 & 21.154 & 41.721 & $\mathrm{p}<0.001$ \\
\hline Error (site) & 44.113 & 87 & 0.507 & & \\
\hline
\end{tabular}




\section{APPENDIX: QUESTIONNAIRE ITEMS}

Consumer Religio-Centrism (adapted from the consumer ethnocentrism scale of Shimp and Sharma, 1987)

[all items rated on a 5 point Likert scale from "strongly disagree" to "strongly agree"]

1. I only purchase products that are in conformity with my religious traditions and beliefs.

2. I only shop from religiously exclusive places (for example Halal shops, Kosher meat shops).

3. I only shop from places whose owners are members of my religion / congregation.

4. Religious consumers, who purchase religiously non-conforming products when a religiously conforming alternative is available, should be banned from the religious community / congregation.

5. I believe that shop owners and manufacturers who follow the same religion / congregation as I do are the ones who should benefit the most from the money I spend on purchases.

6. I hold myself responsible for putting fellow members of my religion / congregation out of business when I buy from places owned by individuals following another religion / congregation.

7. I would buy from shops managed or owned by individuals who are from a different religious / congregational background [reverse].

Religious Commitment (adapted from Stark and Glock, 1968)

[all items rated on 5 point Likert scales]

1. How important is religion to your way of life and your daily decisions? [extremely - not at all]

2. How often do you attend serves such as congregational prayers at your place of worship [once a day or more - never]

3. How often do you pray at home? [once a day or more - never]

4. How important is prayer in your life? [extremely - not at all]

5. How often do you read / recite verses from the scriptures of your holy book? [once a day or more never]

6. How many of your best friends belong to the same religion / congregation as yours? [all - none]

7. How often do you hold religious meetings with fellow members of you religious community? [once a day or more - never]

8. Please circle the appropriate number to indicate your level of agreement/disagreement with the following statement: People without religious beliefs can lead just as moral and useful lives as people with religious beliefs. [strongly agree - strongly disagree] [reverse]

9. Please circle the appropriate number to indicate your level of agreement/disagreement with the following statement: To lead a good life it is necessary to have some religious belief. [strongly agree strongly disagree]

Web-based Attitude (new)

[all items rated on a 5 point Likert scale; items 1-9 are from "strongly disagree" to "strongly agree"]

1. In general I like this site very much.

2. I enjoyed browsing this site.

3. This site seems to me very beneficial.

4. Overall this site is dull. [reverse]

5. I liked the content of this Web site.

6. After I had finished browsing this Web site, I felt happy that there is such a Web site available on the World Wide Web. 
7. This site offers an excellent array of attractive products that I would add to my favourites list.

8. I will definitely revisit this site.

9. This site made me feel at home.

10. How likely would you buy from this site in the nearest future? [definitely will not - definitely will]

\section{Web-based Trust (new)}

[all items rated on a 5 point Likert scale from "extremely" to "not at all"]

1. If you were to buy a product online from this site how confident are you going to be in terms of safety?

2. If you were to buy a product online from this site how confident are you going to be in terms of security?

3. If you were to buy a product online from this site how confident are you going to be in terms of privacy? 